\title{
Tidally induced internal motion in an Arctic fjord
}

\author{
E. Støylen ${ }^{1, *}$ and I. Fer ${ }^{2}$ \\ ${ }^{1}$ Department of Geosciences, University of Oslo, Oslo, Norway \\ ${ }^{2}$ Geophysical Institute, University of Bergen, Bergen, Norway \\ *now at: Norwegian Meteorological Institute, Oslo, Norway \\ Correspondence to: I. Fer (ilker.fer@gfi.uib.no)
}

Received: 7 June 2013 - Revised: 14 October 2013 - Accepted: 2 December 2013 - Published: 10 January 2014

\begin{abstract}
The internal response in a stratified, partially enclosed basin subject to semi-diurnal tidal forcing through a narrow entrance is investigated. The site is located above the critical latitude where linear internal waves of lunar semidiurnal frequency are not permitted to propagate freely. Generation and propagation of tidally induced internal Kelvin waves are studied, for baroclinically sub- and supercritical conditions at the mouth of the fjord, using a non-linear 3-D numerical model in an idealized basin and in Van Mijenfjorden, Svalbard, using a realistic topography. The model results are compared to observations of hydrography and currents made in August 2010. Results from both the model and measurements indicate the presence of internal Kelvin waves, even when conditions at the fjord entrance are supercritical. The entrance of Van Mijenfjorden is split into two sounds. Sensitivity experiments by closing each sound separately reveal that internal Kelvin waves are generated at both sounds. When the conditions are near supercritical, a wave pulse propagates inward from the fjord entrance at the beginning of each inflow phase of the tidal cycle. The leading crest is followed by a series of smaller amplitude waves characterized as non-linear internal solitons. However, higher model resolution is needed to accurately describe the influence of small-scale mixing and processes near the sill crest in establishing the evolution of the flow and internal response in the fjord.
\end{abstract}

\section{Introduction}

Internal waves in the Arctic regions have received increasing scientific interest recently because of their role in vertical mixing and influence on the regional and large-scale heat budget and ice cover. Wind-induced internal waves are important during ice-free conditions in seasonally ice-covered regions, as demonstrated in the northern Chukchi Sea by Rainville and Woodgate (2009). The positive effect of reduced ice cover on internal wave forcing, however, may be offset by increased stratification by meltwater which amplifies the negative effect of boundary layer dissipation on internal wave energy (Guthrie et al., 2013). Another source of internal waves is the action of tidal flow over topography; the Yermak Plateau is noted as an important region for enhanced internal wave activity (e.g. Padman and Dillon, 1991; Fer et al., 2010). In Arctic fjords short period internal waves are observed under ice (Marchenko et al., 2010; Morozov and Marchenko, 2012), and longer period internal Kelvin waves are documented in the Kongsfjorden-Krossfjorden system (Svendsen et al., 2002).

Internal waves in fjords are typically forced by changing winds and the barotropic tide. For fjords that are wide with respect to the internal (baroclinic) Rossby radius, internal Kelvin waves may arise, propagating cyclonically around the fjord. Such waves induce a mean current in the wave propagation direction (Støylen and Weber, 2010), which may lead to an accumulation or deposition of pollutants and biological material in certain areas along the coastline. As discussed in Cottier et al. (2010), fjords in the Arctic are typically wide with respect to the baroclinic Rossby radius. Thus, given sufficient forcing, internal Kelvin waves are to be expected in many stratified Arctic fjords.

In the present work we consider a particular wide, tidally forced Arctic fjord, namely Van Mijenfjorden in Svalbard (Fig. 1). The entrance of this fjord is partly covered by an island, which restricts water inflow to two narrow sounds, and thus makes the fjord a good "laboratory" for process studies (e.g. Widell, 2006; Fer and Widell, 2007). The energy extracted from the barotropic tide, partitioning to tidal jet flux and baroclinic jet flux, as well as the modal contributions to kinetic energy and horizontal shear are discussed 


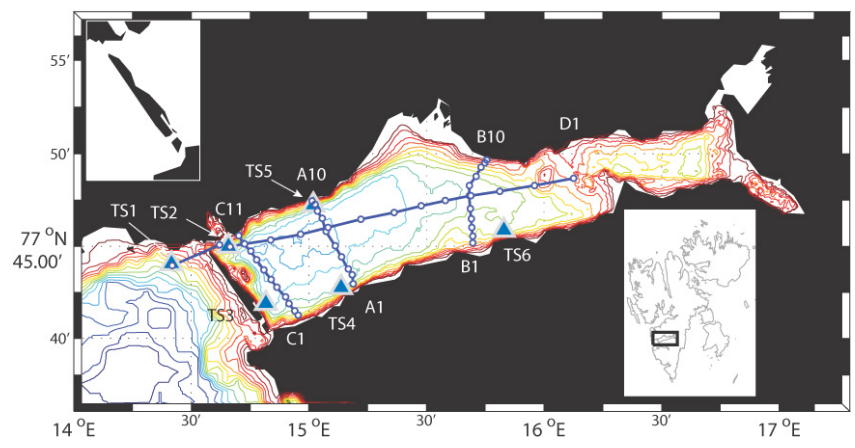

Fig. 1. Map of Van Mijenfjorden in Svalbard, situated at $77.8^{\circ} \mathrm{N}$, $15.5^{\circ} \mathrm{E}$. The insets show (top left) a blow-up of the fjord mouth with the island of Akseløya, and (bottom right) the location of Van Mijenfjord in Svalbard. Lines and dots denote CTD measurement sections (A, B, C, and D) with start and end stations indicated. Triangles marked TS1-TS6 are the time series stations (Table 1).

in Fjellsbø (2013). Our aim is to describe the generation and propagation of internal waves induced by tides in this fjord, by use of recent observations and a 3-D numerical model. In particular, we investigate the possibility of internal Kelvin waves, as suggested in Støylen and Weber (2010) and Skarðhamar and Svendsen (2010). The sensitivity of internal wave generation to hydraulic conditions through the fjord entrance is investigated numerically. Finally, as the fjord entrance consists of two sounds we demonstrate numerically the effect of closing each sound on the respective wave field.

This study is organized as follows: in Sect. 2 we present a theoretical background for internal Kelvin waves in Arctic fjords. Observations from Van Mijenfjorden are given in Sect. 3. In Sect. 4 we treat the numerical problem in an idealized geometry, before applying realistic bottom topography of Van Mijenfjorden. Finally, we discuss our findings and provide concluding remarks in Sect. 5.

\section{Theory}

In this section we briefly discuss what types of internal motion we may expect in an Arctic fjord, and describe a basic theory regarding the internal Kelvin wave. Where appropriate, we will assume a two-layer system with constant densities $\rho_{1}$ and $\rho_{2}$ for the upper and lower layer, respectively. Other variables have similar subscripts. The Cartesian coordinate system $(x, y, z)$ with $z$ as upward vertical direction has corresponding current components $(u, v, w)$.

Internal waves span a broad range of spatial and temporal scales. In a fjord basin there may be propagating Poincaré waves (Brown, 1973; Farmer and Freeland, 1983) and soliton trains (Helfrich and Melville, 2006). Along the coast there may possibly be propagating edge waves (Llewellyn Smith, 2004; Weber and Støylen, 2011) trapped by the sloping bottom, or the internal Kelvin wave trapped by rotation.
The theory behind internal Kelvin waves is well established in the literature (e.g. Gill, 1982). Nonlinearity modifies this solution, as demonstrated in laboratory experiments by Maxworthy (1983), noting a curvature in the cross-wall wave front as well as a modification of the transverse scale $c_{i} / f$, where $f$ is the Coriolis parameter and $c_{i}$ is the baroclinic phase velocity. Later, others confirmed these findings (e.g. Renouard et al., 1987); see Helfrich and Melville (2006) for a comprehensive review. Full 3-D numerical efforts on fjord scale internal Kelvin waves arose during the late 1990s, with a primary focus on closed inland lakes. Beletsky et al. (1997) were among the first to conduct 3-D simulations on this scale, concerning the response in a closed stratified basin (the Great Lakes) to changes in the large-scale wind field. Later numerical studies with increased spatial resolution include Hodges et al. (2000) and Gómez-Giraldo et al. (2006) for Lake Kinneret, Israel.

There are several mechanisms for internal wave generation. In an Arctic fjord, the dominant sources of forcing are the changing wind fields and the barotropic tide interacting with topographic features at the fjord entrance. We will restrict our attention to the tidal case which is particularly relevant for an Arctic fjord that is ice covered. When the crosssectional area of the fjord entrance is narrow, as is the case in Van Mijenfjorden, the tidal current is intensified here. If the water is stratified, one can determine whether conditions are sub- or supercritical with respect to the first baroclinic mode. For a two-layer system, a densimetric Froude number is defined as $F_{\mathrm{D}}=\left|u_{\mathrm{s}}\right| / c_{i}$, where $u_{\mathrm{s}}$ is the upper layer current. $F_{\mathrm{D}}<1$ indicates subcritical conditions, and favours generation of long internal waves. When $F_{\mathrm{D}}>1$, the current enters the fjord as a jet, and there will be a hydraulic jump just inside the entrance. In this case the generation of long waves may be prohibited; we will discuss this further in Sect. 5. For completeness, a derivation of the linear internal Kelvin wave in a two-layer reduced gravity system is given in the following. If the fjord width is large compared to the baroclinic Rossby radius, $a=c_{i} / f$, wave solutions of Kelvin type may exist. In a two-layer reduced gravity system with a deep lower layer, the velocities in the lower layer are neglected. The balance of forces in the lower layer may thus be written as

$$
\begin{aligned}
& g \eta_{x}+P_{\mathrm{S} x} / \rho_{1}=-g^{\prime} \xi_{x} \\
& g \eta_{y}+P_{\mathrm{S} y} / \rho_{1}=-g^{\prime} \xi_{y} .
\end{aligned}
$$

Here $g^{\prime}=g\left(\rho_{2}-\rho_{1}\right) / \rho_{2}$ is the reduced gravity, $P_{\mathrm{S}}$ is surface pressure, $\eta$ and $\xi$ are surface and interface displacements, respectively, and subscripts $x$ and $y$ denote partial derivation. The baroclinic phase velocity is (Gill, 1982)

$c_{i}=\sqrt{\frac{\rho_{2}-\rho_{1}}{\rho_{2}} g \frac{H_{1} H_{2}}{H_{1}+H_{2}}}$,

where $H_{1}$ and $H_{2}$ are the upper and lower layer thicknesses, respectively. If we take a straight coast at $y=0$, the 
Table 1. Overview of observation sections and stations where CTD and LADCP profiles were taken. Names A-D denote horizontal sections, TS1-TS6 time series. A-1 to A-3, B-1 and B-2, and C-1 and C-2 are the re-occupations of the corresponding sections. Time is date of August, and hour $[\mathrm{DD} / \mathrm{HH}]$. Depth $[\mathrm{m}]$ is min-max for sections, average for time series.

\begin{tabular}{llllllll}
\hline Name & B-1 & A-1 & C-1 & TS1 & TS2 & C-2 & TS3 \\
Time & $09 / 20-10 / 00$ & $10 / 02-10 / 04$ & $10 / 06-10 / 09$ & $10 / 10-10 / 23$ & $11 / 00-11 / 13$ & $11 / 13-11 / 16$ & $11 / 17-12 / 06$ \\
No. of samples & 10 & 10 & 11 & 18 & 27 & 11 & 27 \\
Depth & $42-87$ & $61-117$ & $41-110$ & 60 & 60 & $42-114$ & 84 \\
\hline Name & TS4 & A-2 & TS5 & A-3 & B-2 & TS6 & D \\
Time & $12 / 07-12 / 20$ & $12 / 20-12 / 23$ & $12 / 23-13 / 12$ & $13 / 12-13 / 15$ & $13 / 17-13 / 19$ & $13 / 20-14 / 09$ & $14 / 09-14 / 15$ \\
No. of samples & 27 & 10 & 27 & 10 & 11 & 27 & 15 \\
Depth & 79 & $31-112$ & 79 & $32-113$ & $34-88$ & 66 & $33-113$ \\
\hline
\end{tabular}

first-order current component $v_{1}$ is zero everywhere. Inserting from Eq. (1), the linear first order momentum balance in the upper layer becomes

$$
\begin{aligned}
u_{1 t} & =g^{\prime} \xi_{x}+v \nabla_{\mathrm{h}}^{2} u_{1}+v u_{1 z z} \\
f u_{1} & =g^{\prime} \xi_{y},
\end{aligned}
$$

where $v$ is the kinematic viscosity coefficient, and $\nabla_{\mathrm{h}}^{2}$ is the horizontal Laplacian operator. The corresponding linearized continuity equation is obtained by assuming $|\eta| \ll|\xi|$ :

$\xi_{t}=\frac{\partial}{\partial x} \int_{0}^{H_{1}} u_{1} \mathrm{~d} z$.

For the sake of simplicity we neglect the effect of friction here. We consider waves of constant frequency $\omega$ in accordance with steady tidal forcing. A solution to Eqs. (3)(4) is obtained by assuming internal motion of the form $\xi=\xi_{0} e^{-y / a} e^{i(k x-\omega t)}$ with wave number $k$, and near-coast wave amplitude $\xi_{0}$. Letting the real part denote the physical solution, we obtain

$\xi=\xi_{0} e^{-y / a} \cos (k x-\omega t)$

with the corresponding dispersion relation $\omega^{2}=g^{\prime} H_{1} k^{2}$. Equation (5) describes the linear internal Kelvin wave, in accordance with Støylen and Weber (2010). The wave is travelling along the positive $x$ axis on the Northern Hemisphere, the interface displacement is largest near the coast, and is exponentially damped seaward. The frequency of the wave is the forcing frequency; in our case the lunar semi-diurnal $\mathrm{M}_{2}$ tidal component. Retaining the friction term leads to the resulting wave being further damped along the coast (Støylen and Weber, 2010).

Linear wave solutions for free internal Poincaré waves are restricted at the critical latitude where $\omega=f$ for the respective forcing frequency (Vlasenko et al., 2003). For the $\mathrm{M}_{2}$ tidal component the critical latitude is $\phi=74.5^{\circ}$. This restriction does not apply to internal Kelvin waves, however, and they may exist in Arctic regions above the critical latitude (Farmer and Freeland, 1983).

\section{Observations}

Our study site is Van Mijenfjorden in Svalbard; see Fig. 1. This fjord is an interesting "laboratory" for the study of propagating baroclinic waves of tidal periodicity. At the outer region of the fjord the near-coast bathymetry is quite steep. The entrance of the fjord is partly covered by an island, Akseløya. This restricts the water exchange into two narrow sounds, Akselsundet in the north, and Mariasundet in the south. The typical tidal amplitude outside Akseløya is in the range from 0.3 to $0.8 \mathrm{~m}$ (see Fig. 2), and currents measured in Akselsundet may exceed $2 \mathrm{~m} \mathrm{~s}^{-1}$ (Bergh, 2004). During summer and autumn the water in the fjord is stratified as a result of glacial melting. It is during this period that we expect baroclinic tidal activity to be most pronounced. Indeed, using a $22 \mathrm{~h}$ CTD time series near Blixodden in July 1996, Skarðhamar and Svendsen (2010) observed a vertical displacement of the pycnocline of $20 \mathrm{~m}$, which they argued was caused by a passing internal Kelvin wave.

Our measurements were performed in the period between 9 and 14 August 2010 during a cruise of the Research Vessel (R/V) Håkon Mosby. Profiles of hydrography and horizontal currents were collected using a rosette equipped with a Sea-Bird Electronics 911+ CTD (conductivity, temperature, depth) system and a set of up- and down-looking $300 \mathrm{kHz}$, RD Instruments LADCP (lowered acoustic Doppler current profiler). Data were processed using well-established routines and averaged vertically in 1 and $4 \mathrm{~m}$-thick bins for CTD and LADCP, respectively. Weather data were collected from the ship's meteorological mast. Figure 1 shows a map of the measurement locations; see also Table 1. Labels A-D denote horizontal sections, and TS1-TS6 are time series. For each time series station, a profile was obtained approximately every $30 \mathrm{~min}$ for a station occupation period of $13 \mathrm{~h}$, thus encompassing the $\mathrm{M}_{2}$ tidal period of $12.4 \mathrm{~h}$. The location of the stations and the sampling frequency in time were chosen so as to best capture a potentially propagating internal Kelvin wave, which is expected to have its largest amplitude near the coast (see Sect. 2), and propagating cyclonically around the basin. Due to the steep topographic slope near the fjord 

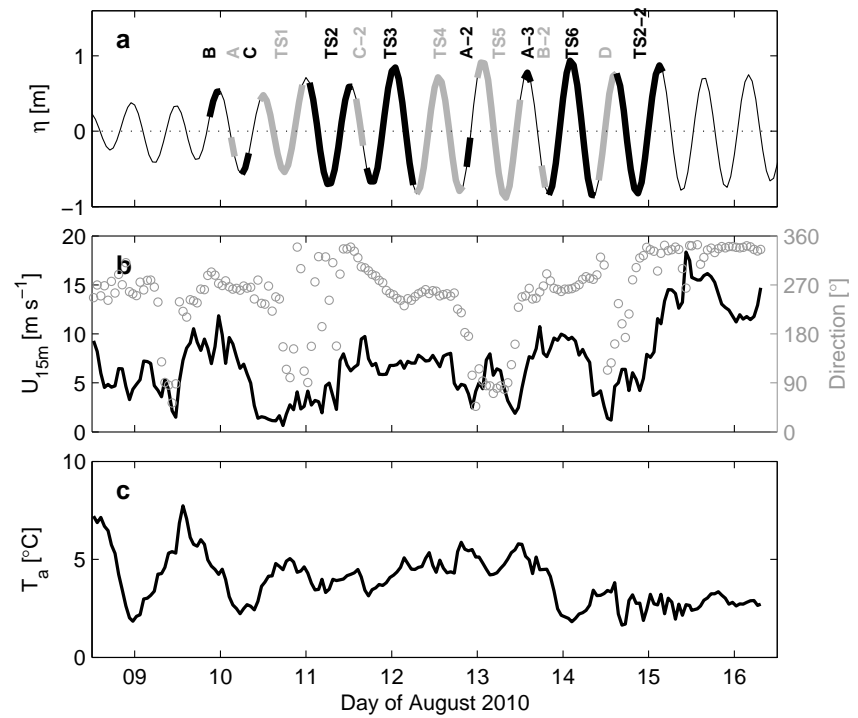

Fig. 2. (a) Tidal surface amplitude outside Van Mijenfjorden inferred at the location of TS1 from the AOTIM-5 model (Padman and Erofeeva, 2004). Alternating thick grey and black portions represent the time of occupation of the sections and the time series stations indicated by letters. Several sections were repeated, e.g. A-2 corresponds to the second occupation of section A. Time series of hourly averaged (b) wind direction and speed, and (c) air temperature, measured from the meteorological mast onboard R/V Håkon Mosby at $15 \mathrm{~m}$ height.

entrance and strong tidal forcing, in addition to the long internal Kelvin waves, short non-linear solitary waves are expected (see e.g. Farmer and Armi, 1999; Grue et al., 1999; Cummins et al., 2003). These short wavelength and highfrequency phenomena are, however, not resolved with our sampling scheme, and will be treated further in the numerical analysis (Sect. 4). The narrow sound combined with swift currents posed severe navigational difficulties and hindered a detailed, high-time and spatial resolution sampling near the sill region.

A general view of the hydrography in the basin is presented in Fig. 3. The stratification is typical for this season. Surface water is relatively fresh as a result of summer melt and runoff from glaciers, and warmer than the water below due to surface heating; see Fig. 2 for air temperature measurements. The colder and saltier deep water seen in Fig. 3a) originates from outside the fjord. During high tide this water is lifted over the sill as can be inferred from the D-section; the outmost D-profile was the last sample in the section, and was thus captured during high tide; see Fig. 2. The repeated sections $\mathrm{B}$ and $\mathrm{C}$ indicate a strong variability on relatively short time scales throughout the entire fjord basin (Fig. 3). This is in accordance with Skarðhamar and Svendsen (2010), where a more detailed description of the short-term hydrographic variability in Van Mijenfjorden can be found. In the present work we restrict our attention to the internal waves.
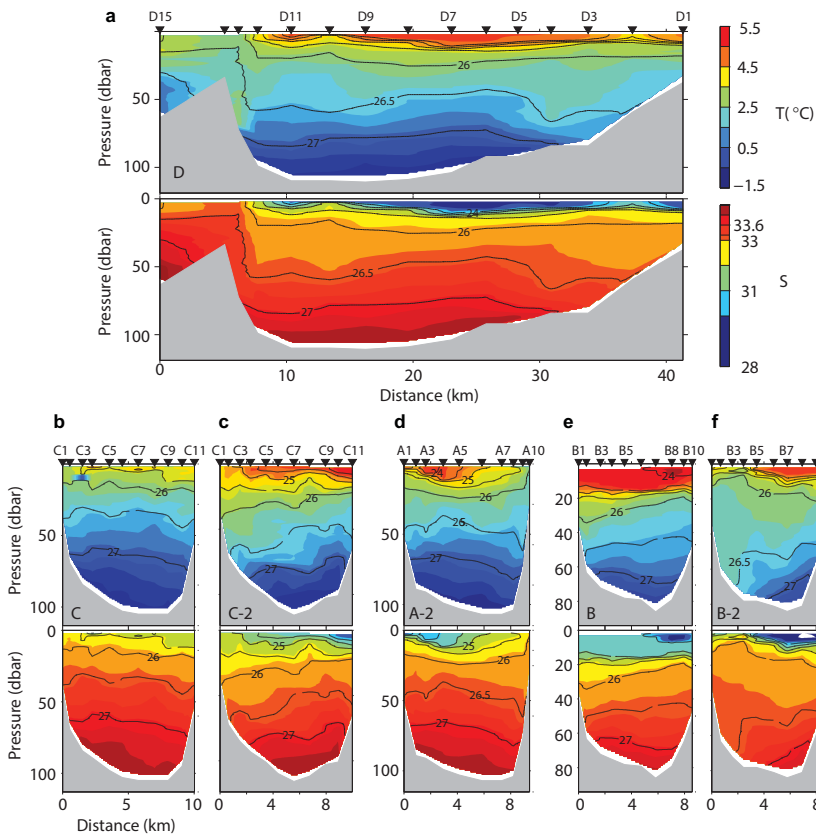

d
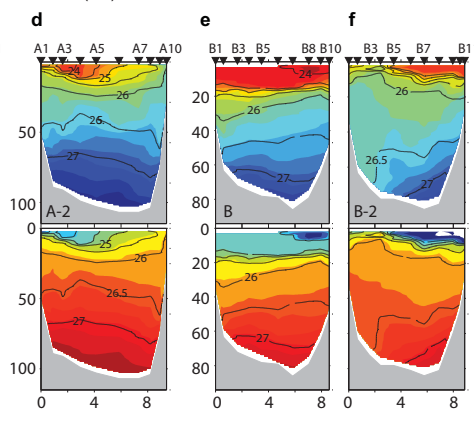

Fig. 3. Temperature and salinity (colour) and density (black contours) for CTD sections (a) D, (b) C-1, (c) C-2, (d) A-2, (e) B-1, and (f) B-2. Orientation of the figures is west-east in (a), and southnorth in (b)-(f). See Fig. 1 and Table 1 for reference.

Time-depth contours of velocity and density for each time series station are presented in Fig. 4. Again we refer to Fig. 2 for comparison with the tide. Outside Akseløya (TS1) the dominant features of the tide entering and leaving Akselsundet are distinguishable in the upper $40 \mathrm{~m}$. Just inside Akselsundet (TS2) we observe intense mixing associated with the peak tidal inflow. The small-scale overturning and mixing associated with this hydraulic jump will influence the generation of long waves in the lee of the sill; see discussion in Sect. 5. An intensified inflow may also contribute to generation of short non-linear solitons, as we observe in the numerical experiments reported in Sect. 4. Further south, along Akseløya north of Mariasundet (TS3), the flow field is dominated by a southward current that is related to the time of maximum tidal inflow through Akselsundet. Assuming a typical current velocity of $35 \mathrm{cms}^{-1}$ as measured at TS3 and a distance between Askelsundet and the TS3 station of $7.5 \mathrm{~km}$, we obtain a travel time of about $6 \mathrm{~h}$ in agreement with the time of tidal inflow inside Akselsundet. We note the displacements of the isopycnals which weakly indicate oscillations of tidal periodicity. Along the southern coast (TS4) the currents are in-fjord during the entire tidal period. This station is potentially influenced by inflow from both sounds, thus a more complex current structure is expected. Interestingly, the isopycnals are displaced vertically by more than $30 \mathrm{~m}$ during the time series, accompanied by a clear vertical shift in the horizontal current. A similar displacement is not observed along the northern coast (TS5). The observations from the 

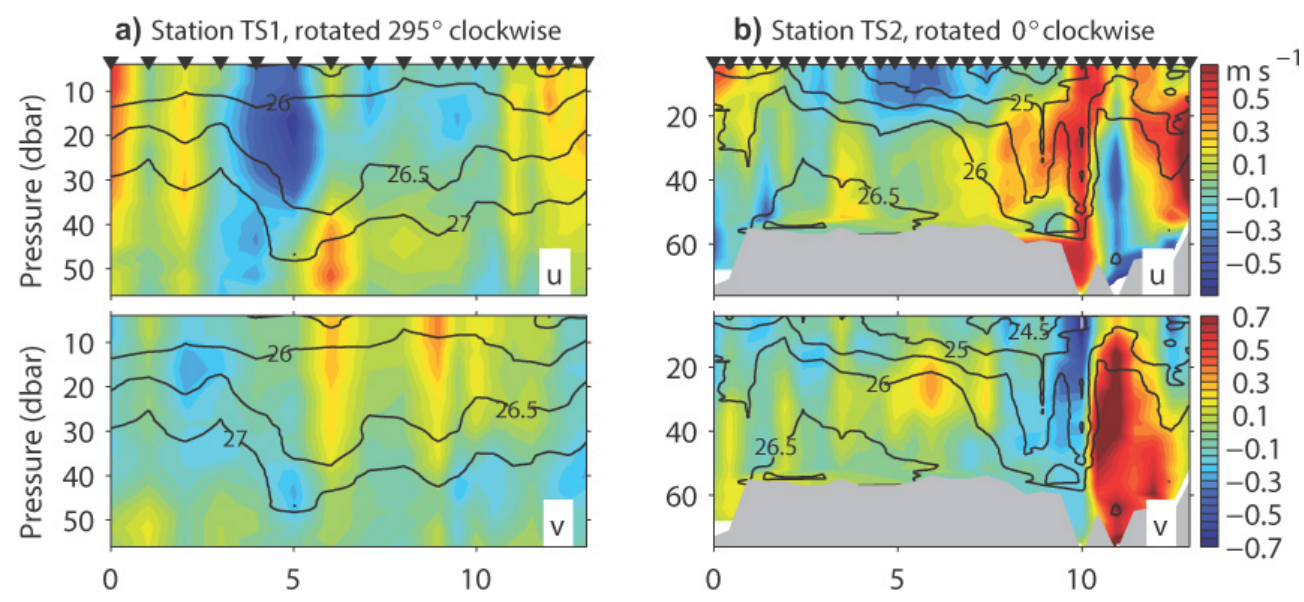

c) Station TS3, rotated $62^{\circ}$ clockwise
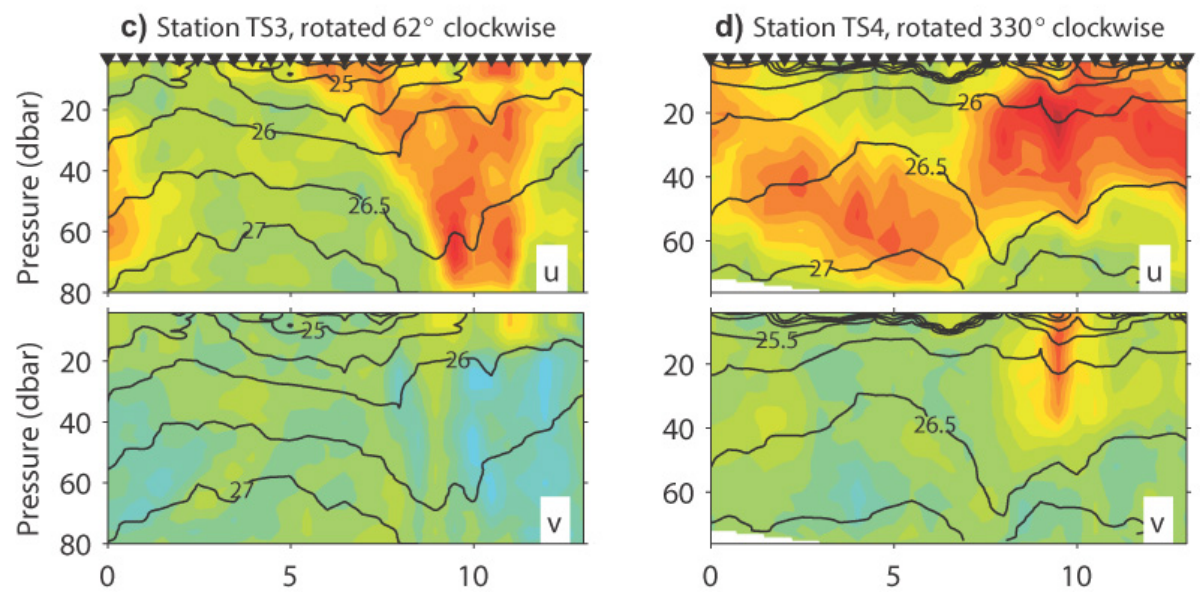

e) Station TS5, rotated $340^{\circ}$ clockwise
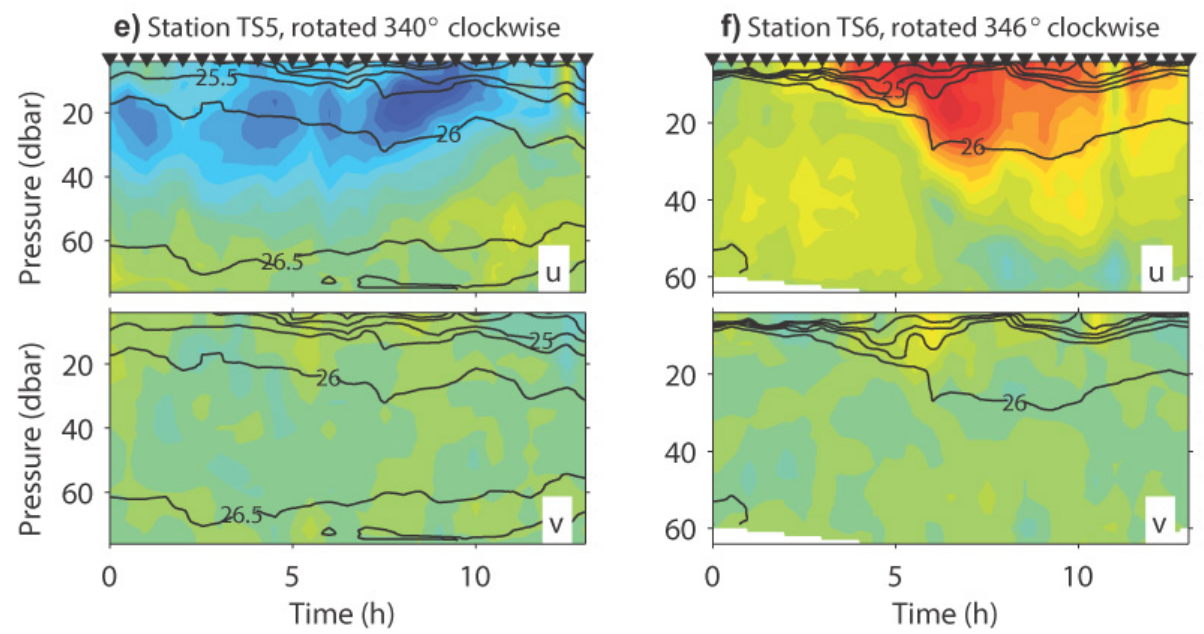

Fig. 4. $u$ and $v$ velocities (colour) and density ( $\sigma_{\text {thet }}$, black contours) for each time series station. (a)-(f) correspond to TS1-TS6 respectively. Axes are rotated so that $u$ is aligned eastward along the coast where applicable (TS3-TS6), or along a direct line inwards through Akselsundet (TS1-TS2).

time series stations suggest the presence of an internal Kelvin wave propagating in-fjord from Akseløya along the southern coast, and dissipating before returning outward along the northern side. The role of Mariasundet in this process is difficult to assess (Sect. 4). The main outflow along TS5, and the dominant eastward flow along the southern slope at TS4 and TS6 are consistent with Kelvin waves and the mean circulation in Van Mijenfjorden induced by the tidal forcing (Bergh, 2004). 
Time series of horizontal velocity and density profiles collected at stations TS1 to TS6 are used to calculate the baroclinic energy flux for the semi-diurnal signal

$\boldsymbol{F}_{E}(z)=\left\langle\boldsymbol{u}^{\prime} p^{\prime}\right\rangle_{\varphi}$

where $\boldsymbol{u}^{\prime}$ is the baroclinic perturbation velocity vector, $p^{\prime}$ is the pressure perturbation, and averaging is over the $\mathrm{M}_{2}$ phase, $\varphi$. The calculations are made following the methods detailed in Nash et al. (2005). The pressure anomaly is inferred from the density profiles assuming hydrostatic balance, after removing the full depth average to satisfy baroclinicity. The perturbation velocity is calculated from the LADCP profiles after removing the depth and time average. The semi-diurnal components for the pressure and velocity perturbations are then isolated by harmonic analysis of time series at each depth level. Using the amplitude and phase obtained from the harmonic analysis, one cycle of a sinusoidal semi-diurnal wave is constructed, and time averaging is done over one complete phase. The depth integrated fluxes are shown in Fig. 5. The semi-diurnal baroclinic energy is generated at the fjord sill, in both in-fjord and out-fjord directions. The in-fjord energy propagates cyclonically along the slope, decaying in magnitude, presumably due to friction. The observations of the baroclinic semi-diurnal energy flux are consistent with Kelvin waves.

The depth of the isopycnal $\sigma_{\theta}=26$ at TS2 gradually decreases from about $11 \mathrm{~m}$ to approximately $59 \mathrm{~m}$, close to the seabed, which then abruptly rises to $19 \mathrm{~m}$ in $2 \mathrm{~h}$. The details of this transition are not resolved by our observations. The evolution of the stratification at TS2 is complex, and a twolayer approximation is not possible. Nevertheless, between 2 and $7 \mathrm{~h}$ into the record, when the isopyncals are relatively smooth, the depth of the pycnocline, inferred from the depth of the maximum in vertical density gradient, is $15 \pm 4 \mathrm{~m}$ ( \pm one standard deviation); the depth of the $\sigma_{\theta}=26$ surface during this period is approximately $22 \mathrm{~m}$. Assuming that the pynocline depth is representative of the upper layer thickness in a two-layer flow, this vertical displacement corresponds to a normalized excursion (vertical displacement divided by the upper layer thickness) of 2.7 , or 1.8 when normalized by the mean depth of the isopycnal.

At TS4, large vertical isopycnal displacements occur in the relatively weakly stratified portion of the water column. This is expected through the WKB scaling, since less energy is required to vertically displace the isopycnals in weaker stratification. The vertical excursion of $\sigma_{\theta}=26.5$ surface is $37 \mathrm{~m}$ in approximately $2 \mathrm{~h}$. This isopycnal is located at $40 \mathrm{~m}$ depth on average, corresponding to a normalized excursion of 0.9 . The stratification is strongest in the upper layers, and the pycnocline depth is estimated at $6 \pm 2 \mathrm{~m}$ using all the profiles. The typical vertical displacement in the pycnocline, using the 25 isopycnal, is $4-6 \mathrm{~m}$, yielding a normalized excursion close to 1 . The exact period of the wave at TS4 (or at other stations) cannot be inferred from the time series with confidence because of the short duration of the record. While the

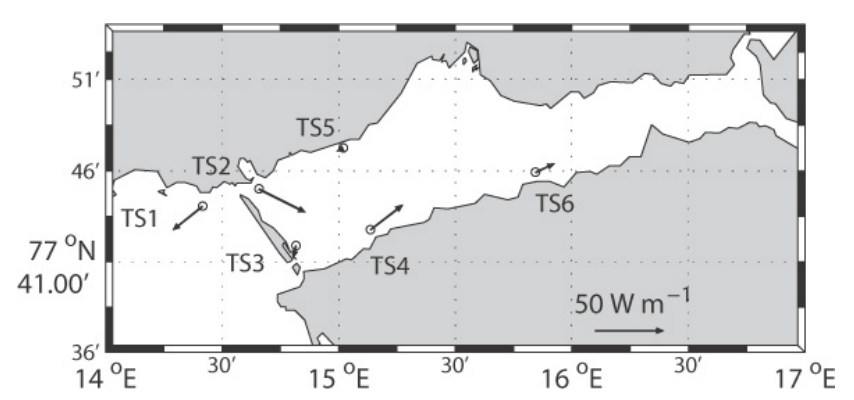

Fig. 5. Depth-integrated semi-diurnal baroclinic energy flux vectors inferred from the time series stations. The scale is shown on the bottom right.

semi-diurnal period fits explain up to $50 \%$ of the total variance, the wave period inferred from the first zero crossing of the autocovariance function is $8 \mathrm{~h}$ for the $\sigma_{\theta}=26$ and 26.5 isopycnals, and increases to $5 \mathrm{~h}$ for the isopycnals in the pycnocline $\left(\sigma_{\theta}=25\right.$ and 25.5). A similar analysis for the alongshore component of the baroclinic velocity suggests consistent periods $(5.2 \mathrm{~h}$ at $8 \mathrm{~m}$ depth, and $9 \pm 0.6 \mathrm{~h}$ between 12 and $68 \mathrm{~m})$. The pattern is similar at TS3; the $\sigma_{\theta}=26.5$ isopycnal oscillates at $8 \mathrm{~h}$, and the oscillation of the rotated baroclinic velocity component is between 7 and $10 \mathrm{~h}$ throughout the water column.

\section{Numerical simulations}

\subsection{Model and the setup}

The model utilized is the MITgcm model (Marshall et al., 1997; Adcroft et al., 2004). This is a finite volume, nonlinear $z$ coordinate model with non-hydrostatic capabilities. The model has been widely used for study of internal waves (Legg and Adcroft, 2003; Vlasenko and Stashchuk, 2007; Xing and Davies, 2007; Boegman and Dorostkar, 2011). Bottom topography in MITgcm is represented by the use of shaved cells (Adcroft et al., 1997). For our model setup we disregard the effect of diffusion by setting small constant values for the horizontal and vertical diffusivities of temperature and salt ${ }^{1}$. We use a vertical turbulent viscosity of $A_{z}=0.001 \mathrm{~m}^{2} \mathrm{~s}^{-1}$. The horizontal viscosity is of Smagorinsky type with value 2.2 along with a small biharmonic viscosity factor (viscC4smag $=1$ ) as suggested by Griffies and Hallberg (2000). No-slip conditions are employed at side walls, along with a quadratic bottom drag coefficient of 0.0025 . The time step used is $5 \mathrm{~s}$, the horizontal grid size is $100 \mathrm{~m}$, and we employ 32 non-uniformly spaced vertical levels with the lowest spacing of $0.75 \mathrm{~m}$ where the density gradient is largest, and up to $14 \mathrm{~m}$ spacing below $100 \mathrm{~m}$ depth. We let the model run hydrostatically, as the grid should be too coarse for nonhydrostatic effects to be observable (Berntsen et al., 2009).

\footnotetext{
${ }^{1} K_{\mathrm{hT}}=1 \times 10^{-6}, K_{\mathrm{zT}}$
$0^{-9} \mathrm{~m}^{2} \mathrm{~s}^{-1}$
} 
In our simulations we ignore the effect of wind and freshwater runoff. Initially, the system is at rest, with horizontally constant hydrography. The hydrography of Van Mijenfjorden varies considerably on short time scales (Sect. 3). Performing a realistic simulation of the entire fjord system requires detailed information on local winds and freshwater runoff, and detailed initial and boundary conditions on hydrography and currents. In this study, we focus on the generation and propagation of internal waves. Thus, it is instructive to idealize the problem. In the following we describe the idealized box runs, and subsequently, the relatively realistic Van Mijenfjord runs.

\subsection{Idealized box runs}

We shall consider the Van Mijenfjord topography in Sect. 4.3, but in this section we use a simplified semienclosed box with the topography shown in Fig. 6. The the long side, $x$ axis, is aligned in the west-east direction, and the short side, $y$ axis, along south-north. The western boundary is open, whereas all other boundaries are closed. At $20 \mathrm{~km}$ in-fjord, we place a constriction resembling Akseløya. In this simplified setup we only consider one sound (recall that Van Mijenfjorden has two sounds), and place it on the southern side in order to avoid the complicating factor of the wave making a $90^{\circ}$ turn in the southwestern corner. The sound is $20 \mathrm{~m}$ deep and $1300 \mathrm{~m}$ wide, giving a crosssectional area similar to Akselsundet. The sloping bottom toward the eastern coast is introduced as a crude wave damper to minimize reflections. The open boundary condition is of the form $u=u_{0} \sin (\omega t)$, where $u_{0}$ is constant across the open boundary and $\omega=1.4 \times 10^{-4} \mathrm{~s}^{-1}$ corresponds to the $\mathrm{M}_{2}$ semi-diurnal tide. The interior solution is relaxed toward the boundary over a 64 -grid point wide sponge layer. The relaxation time scale increases linearly with distance from the open boundary, up to $16 \mathrm{~h}$ at the inner border of the sponge layer. The model is initiated with a forcing amplitude of $u_{0} / 2$ in the first $6 \mathrm{~h}$ to ensure a smooth spin-up, and run for $48 \mathrm{~h}$.

The solution is dependent on the choice of the forcing amplitude $u_{0}$ and the vertical hydrography profile. In the following, we use our idealized setup to test the internal response of the system by varying these parameters.

\subsubsection{Box run 1: Van Mijenfjord hydrography}

In the first test, we set forcing and hydrography to resemble the conditions in Van Mijenfjorden. From Fig. 2, we want surface tidal amplitudes close to $0.5 \mathrm{~m}$. If we integrate over the domain this leads approximately to a boundary forcing of $u_{0}=3 \mathrm{~cm} \mathrm{~s}^{-1}$ (verified a posteriori). Regarding the hydrography, we neglect the effect of horizontal variation, and consider only the outer part of the fjord. Representative profiles of temperature, salinity, and density are obtained by averaging the CTD measurements from the time series stations TS2-TS5, and the sections A and C (Fig. 7).

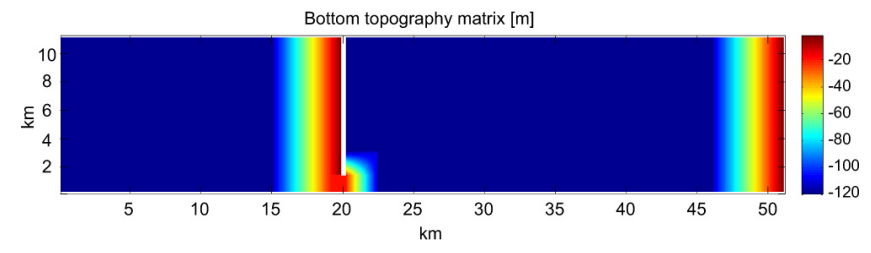

Fig. 6. Bottom topography test box run. The western boundary is the only open boundary.
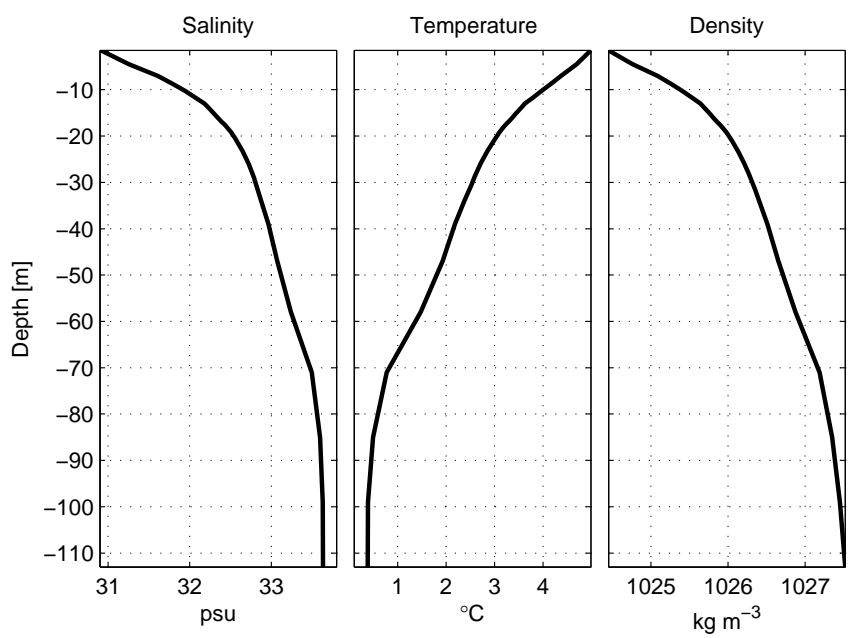

Fig. 7. Initial hydrography for box run 1.

In order to visualize the horizontal distribution of the vertical isopycnal displacements, we introduce a perturbation potential energy per unit area, defined as

$$
\Delta \mathrm{PE}(t)=\mathrm{PE}(t)-\mathrm{PE}_{0}=\int_{-H}^{\eta(t)} \rho(t) g z \mathrm{~d} z-\int_{-H}^{0} \rho(t=0) g z \mathrm{~d} z .
$$

From this definition $\mathrm{PE}$ is negative, so a positive $\triangle \mathrm{PE}$ indicates a mean depression in the water column. Plot of the normalized $\triangle \mathrm{PE} 41 \mathrm{~h}$ into the simulation is shown in Fig. 8. The region shown is from 20 to $45 \mathrm{~km}$ in-fjord, i.e. the sound is immediately in the southwestern corner, and the eastern-most region with the sloping bottom is omitted. We clearly see that the most energetic displacements occur near the boundaries. These displacements propagate cyclonically around the basin, similar to internal Kelvin waves. The radius of the displacement signal is $2-3 \mathrm{~km}$, and by comparing similar plots at different times we obtain a propagation velocity of 40 $45 \mathrm{~cm} \mathrm{~s}^{-1}$ (not shown). A similar velocity can be inferred from $\lambda / T_{M 2}=42 \mathrm{~cm} \mathrm{~s}^{-1}$, using a wavelength of $\lambda=19 \mathrm{~km}$ obtained from Fig. 8, and the wave period $T_{M 2}=12.42 \mathrm{~h}$. Here, $c_{i}=42 \mathrm{~cm} \mathrm{~s}^{-1}$ is taken as the typical internal long wave speed for this model configuration.

In addition to the internal Kelvin wave signal, a second feature is evident in Fig. 8. In front of the coastal wave, there is a narrow pulse, a non-linear soliton that propagates radially 


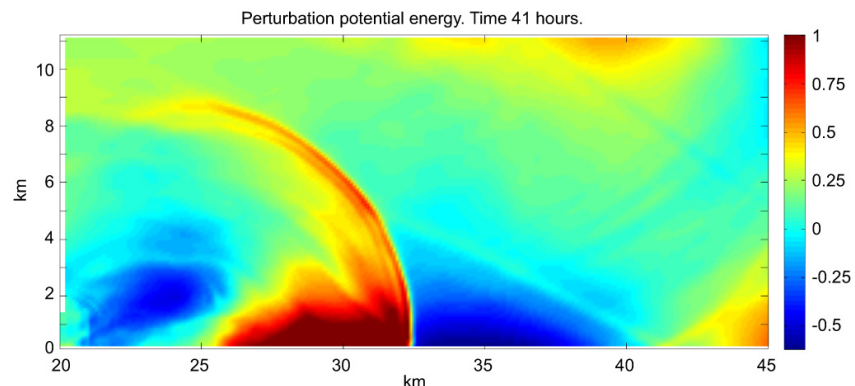

Fig. 8. Horizontal plot of normalized perturbation potential energy $\triangle \mathrm{PE}$ after $41 \mathrm{~h}$, box run 1 . The plotted region corresponds to the first $25 \mathrm{~km}$ of the inner basin; see Fig. 6. Red and blue indicate depression and elevation respectively; see Fig. 9.

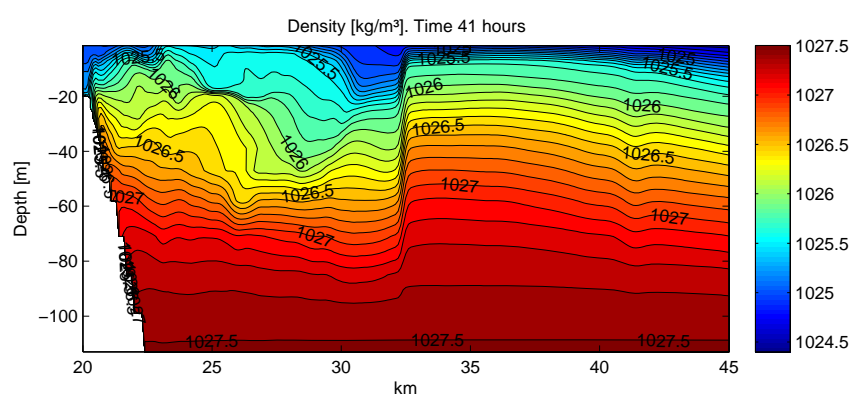

Fig. 9. Vertical section of density near the southern coast between 20 and $45 \mathrm{~km}$ east after $41 \mathrm{~h}$ simulation, box run 1 . Contour interval is $0.1 \mathrm{~kg} \mathrm{~m}^{-3}$.

into the basin in all directions from the sound. By inspection of the circular shape of the leading wave crest, we infer that the propagation velocity is approximately constant in all directions. Model output from successive time steps indicates that the velocity of the pulse is similar to the internal long wave speed $c_{i}$ (not shown). From a vertical section of density near the southern wall, at $y=100 \mathrm{~m}$ (Fig. 9), we see more clearly the steep front of the depression, coinciding with the pulse. The vertical displacement exceeds $20 \mathrm{~m}$ over a $600 \mathrm{~m}$ horizontal distance. We discuss this pulse more thoroughly in Sect. 5.

We now turn our attention to the velocities through the sound. A vertical cross section of normalized maximum velocity $u_{\mathrm{s}} / c_{i}$ across the sound is presented in Fig. 10. During inflow the current peaks at $3.69\left(1.55 \mathrm{~m} \mathrm{~s}^{-1}\right)$ in a jet at approximately $16 \mathrm{~m}$ depth. The outflow is relatively homogenous across the sound, peaking at $-3.07\left(-1.29 \mathrm{~m} \mathrm{~s}^{-1}\right)$. This asymmetry is expected in accordance with tidal choking theory (Stigebrandt, 1980). Further, these values relate directly to the definition of the Froude number (Sect. 2). $F_{\mathrm{D}} \approx 3$ is a clear indication of supercritical conditions, reinforcing the jet-type behaviour shown in Fig. 10.
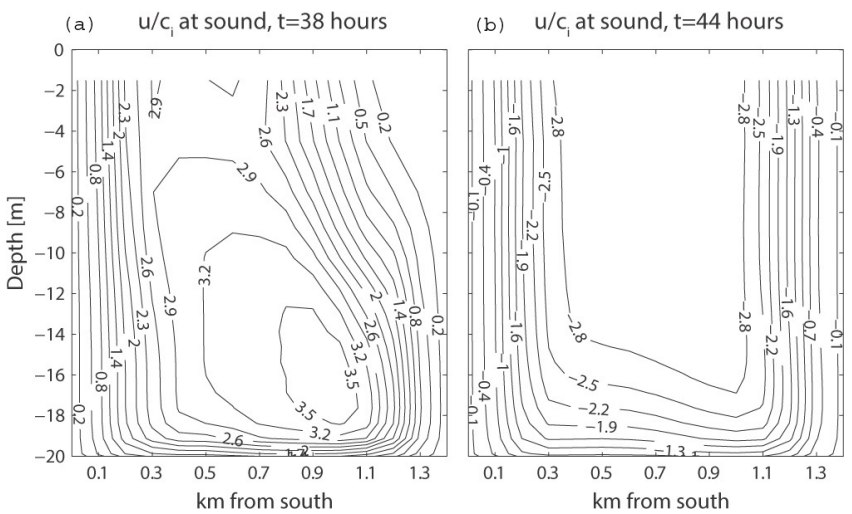

Fig. 10. Cross-sectional velocity $\left[\mathrm{ms}^{-1}\right]$ at time of maximum inflow (a) and outflow (b) through the sound at $20 \mathrm{~km}$ east for box run 1. Left-right in the figures correspond to south-north.

\subsubsection{Box run 2: Two-layer stratification}

Having obtained the expected baroclinic phase velocities $\left(c_{i}\right)$ from a realistic stratification, we set up a case with two-layer stratification. We preserve the approximate location of the pycnocline while keeping the typical value of $c_{i}$. For simplicity, we take temperature constant at $2^{\circ} \mathrm{C}$, and a two-layer salinity profile as shown in Fig. 11. The resulting density is also shown, in which a small correction for pressure can be seen. The phase velocity $c_{i}$ is calculated according to Eq. (2), which yields $c_{i}=0.42 \mathrm{~m} \mathrm{~s}^{-1}$ using the appropriate values from Fig. 11.

Plot of $\triangle \mathrm{PE}$ for the two-layer stratification after $41 \mathrm{~h} \mathrm{sim}$ ulation is shown in Fig. 12. The structure is comparable to the previous case, with most of the energy near the south coast, and a similar pulse propagating into the basin. A vertical section near the south coast (Fig. 13) reveals that most of the displacement occurs near the pycnocline, and a steepened structure similar to Fig. 9 is seen. The normalized velocities through the sound (not shown) are very similar to the previous case in structure, with the maximum values of $3.61\left(1.52 \mathrm{~m} \mathrm{~s}^{-1}\right)$ and $-3.07\left(-1.29 \mathrm{~m} \mathrm{~s}^{-1}\right)$, during the inflows and outflows, respectively.

\subsubsection{Box run 3: Test forcing}

In the next set of tests we consider the sub-critical scenario by reducing the forcing amplitude. We perform two runs using the two-layer hydrography from box run 2 , with $u_{0}=0.45 \mathrm{~cm} \mathrm{~s}^{-1}$ and $0.9 \mathrm{~cm} \mathrm{~s}^{-1}$, or $15 \%$ (a) and $30 \%$ (b) of the original forcing, respectively. $\triangle \mathrm{PE}$ for the two runs are presented in Fig. 14. We clearly see the difference between the two cases; at case a, the pulse in front of the coastal wave is almost absent and the shape is quite similar to what we expect from a Kelvin wave (i.e. Eq. 5). At case b, however, the pulse is more visible, and the shape is reminiscent of the result for the box run 2 . 


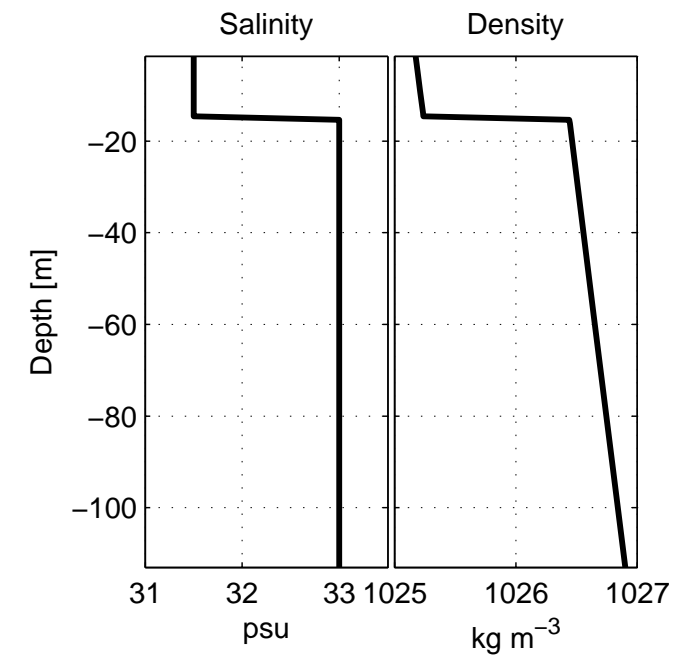

Fig. 11. Initial hydrography for box run 2 . Temperature is constant at $2{ }^{\circ} \mathrm{C}$ and not shown.

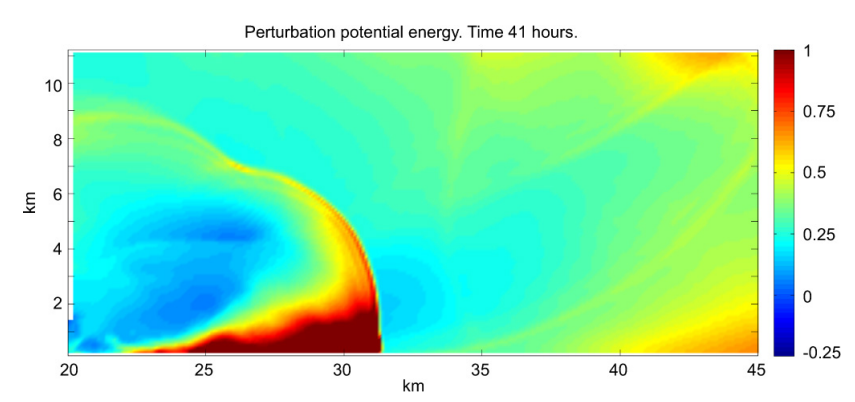

Fig. 12. Normalized $\triangle \mathrm{PE}$ (similar to Fig. 8) after $41 \mathrm{~h}$ simulation, box run 2 .

The normalized velocities through the sound have maximum values of $-0.57\left(-0.24 \mathrm{~m} \mathrm{~s}^{-1}\right)$ and $0.67\left(0.28 \mathrm{~m} \mathrm{~s}^{-1}\right)$ for case a, and of $-1.07\left(-0.45 \mathrm{~m} \mathrm{~s}^{-1}\right)$ and $1.33\left(0.56 \mathrm{~m} \mathrm{~s}^{-1}\right)$ for case $b$. The velocity structure across the sound in the latter case is similar to box run 2 with a jet during inflows and a more barotropic distribution during outflows. The jet is not as visible in case $a$, however; here the structure is rather similar for in- and outflow, in accordance with the subcritical conditions reflected by the normalized velocities.

\subsection{Van Mijenfjord runs and comparison with observations}

Having obtained some experience with the idealized model runs, we now apply a topography similar to Van Mijenfjorden. As this fjord has two sounds, it is of interest to isolate the effect of each sound. We also investigate the influence of the realistic hydrography in comparison with the two-layer structure we applied in Sect. 4.2.2.

We set up four model runs with different topography and initial hydrography; see Table 2 . The bottom topography matrix is shown in Fig. 15. The leftmost part is the sponge layer,

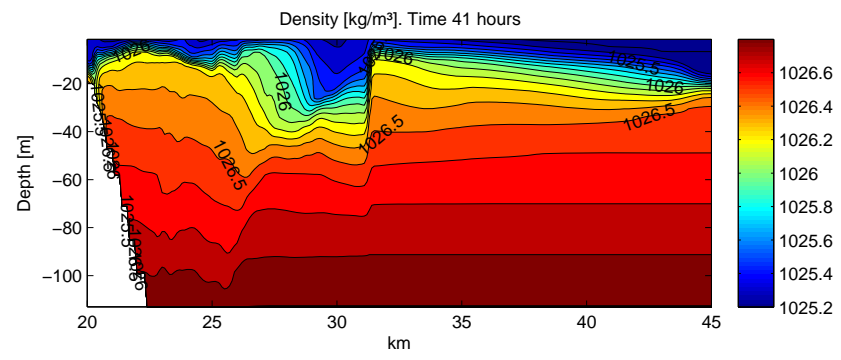

Fig. 13. Vertical section of density near southern coast after $41 \mathrm{~h}$ simulation, box run 2. Contour interval is $0.1 \mathrm{~kg} \mathrm{~m}^{-3}$.
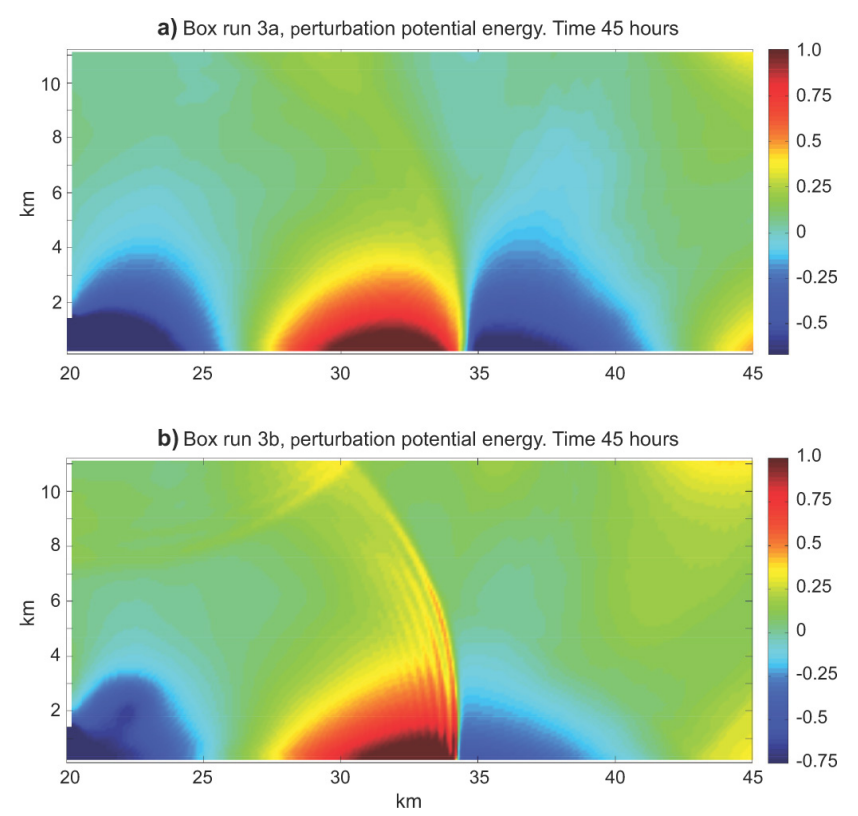

Fig. 14. Normalized $\triangle \mathrm{PE}$ (similar to Fig. 8) after $45 \mathrm{~h}$ simulation, box run 3 . Forcing at $15 \%$ (a) and $30 \%$ (b) of original forcing.

and the shallow, secondary inner basin on the east of Van Mijenfjorden is omitted from the simulation. As our point of interest is close to Akseløya, this should not influence our solution significantly. When a sound is closed, we simply set the depth to zero in a three grid point-wide band across the respective sound. Model parameters are similar to what is used in Sect. 4. As a result of varying depth, $\triangle \mathrm{PE}$ (Eq. 7) is not easily visualized; instead, contours of constant density are shown.

Results from the first run with realistic hydrography and topography (VMrun1) are shown in Fig. 16. The left column shows the density distribution at three different depths after $45 \mathrm{~h}$ simulation, whereas the right column shows the structure at $-16.9 \mathrm{~m}$ depth at different times. As before, we identify the internal Kelvin wave pattern along the southern coast. It is quite visible at all three depths, but most pronounced at $-16.9 \mathrm{~m}$. Snapshots at different times suggest that the primary internal wave generation occurs at Akselsundet. We also note the pulse at all depths. Current magnitude and 
Table 2. Setup of the four Van Mijenfjorden model runs.

\begin{tabular}{lllll}
\hline & VMrun1 & VMrun2 & VMrun3 & VMrun4 \\
\hline Topography: & Realistic & Mariasundet closed & Akselsundet closed & Realistic \\
Hydrography: & Realistic & Realistic & Realistic & Two-layer
\end{tabular}

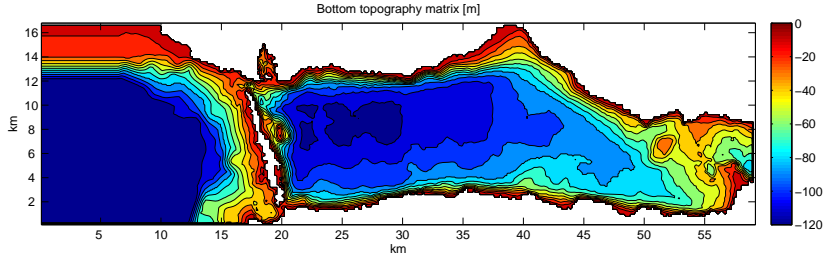

Fig. 15. Bottom topography of Van Mijenfjorden.

direction at $-16.9 \mathrm{~m}$ depth are shown in Fig. 17 at the time of maximum inflow (a) and maximum outflow (b) through Akselsundet. We see the wave along the southern coast propagating inward at all times through the tidal cycle. Near Akselsundet during inflow, the current has a dominantly southeastern direction along Akseløya. During outflow the current is toward the sound from a much wider region, in accordance with tidal choking theory discussed earlier. Current amplitudes through Akselsundet reach 1.4-1.6 m s${ }^{-1}$, consistent with observations from moored current meters (Bergh, 2004; Fer and Widell, 2007; Fjellsbø, 2013).

As a means of comparing the realistic model run with the measurements, we plot model density and along-coastal current at the time series locations TS4 and TS5 (Fig. 18). For the station near the southern boundary (TS4), the largest currents coincide with depression of the isopycnals (low-density values) in the upper layer (see also Figs. 16 and 17). The excursion of the 25.5 isopycnal, located at $14 \mathrm{~m}$ on average, is $13 \mathrm{~m}$ over the tidal period, corresponding to a normalized excursion of 0.9 . We also see a local current maximum around $-60 \mathrm{~m}$ depth along with elevation of the isopycnals. This is also observed in the measurements (Fig. 4d). The current magnitude and the maximum isopycnal displacement are lower than what was measured. At the northern station TS5 (Fig. 18b), we see only small oscillations, consistent with the observations. The strong mean westward flow in the upper layer in the measurements at TS5 (Fig. 4e) is not present in the model because of model shortcomings and simplifications; see Sect. 5.

The next two model runs are presented in Fig. 19. Here we experiment with closing Mariasundet (VMrun2, left column) and Akselsundet (VMrun3, right column) separately. The result when the Mariasundet is closed is quite similar to what was found in the realistic run (Fig. 16), suggesting that Akselsundet is the dominant generator for internal waves. However, as we see in VMrun3, closing off Akselsundet reveals a substantial contribution from Mariasundet. Comparing the location of the largest depression from the two runs, we in- fer that waves in VMrun2 are only about $2-3 \mathrm{~km}$ ahead of those in VMrun3. Thus the full picture in VMrun1 is close to a superposition of two internal Kelvin waves. Regarding the pulse we note that it is clearly visible in all the plotted depths, propagating radially from each respective sound.

As a last test, we apply the two-layer hydrography with the realistic topography (VMrun4). The result is shown in Fig. 20 for $-16.9 \mathrm{~m}$ depth. Again, a Kelvin-type signal can be identified, along with several pulses. At -10.3 and $-28 \mathrm{~m}$ depths, the density surfaces are approximately undisturbed (not shown).

\section{Discussion and concluding remarks}

Through a series of simulations and measurements, we have shown strong indications of tidally induced internal wave motion in Van Mijenfjorden, an Arctic fjord in Svalbard. As expected, a major part of the internal wave energy is in the form of an internal Kelvin wave, propagating cyclonically around the fjord. Numerical tests using a two-layer stratification show that the propagating internal wave emerges when conditions at the sound are baroclinically sub- or supercritical. This is in agreement with observations from Loch Etive, Scotland (Inall et al., 2004; Stashchuk et al., 2007), which is a typical "jet-type" fjord following the definition of Stigebrandt and Aure (1989). According to Stigebrandt (1980), generation of long waves in a jet fjord is prohibited, although he notes that for weakly supercritical conditions wave generation cannot be ruled out.

Our results indicate that both sounds in Van Mijenfjorden serve as internal wave generators; the dominant waves propagate from Akselsundet, whereas the contribution from Mariasundet can be substantial. According to the model results, a realistic summer hydrography leads to waves generated from the two sounds that are approximately in phase. As propagation velocity is directly affected by the stratification, waves from the two sounds are likely to be in phase occasionally, because of the considerable variability in hydrography. Consequently, the contribution from each respective sound may be masked in measurements. It is important to note that Mariasundet is relatively narrow $(0.7 \mathrm{~km}$ wide $)$ compared to the grid size $(100 \mathrm{~m})$, and the representation of this sound in the topography matrix is coarse. Increasing the resolution and applying a more accurate representation of the topography would thus contribute to a more realistic wave field.

Increasing the resolution and including non-hydrostatic terms in the model equations can help resolve the 

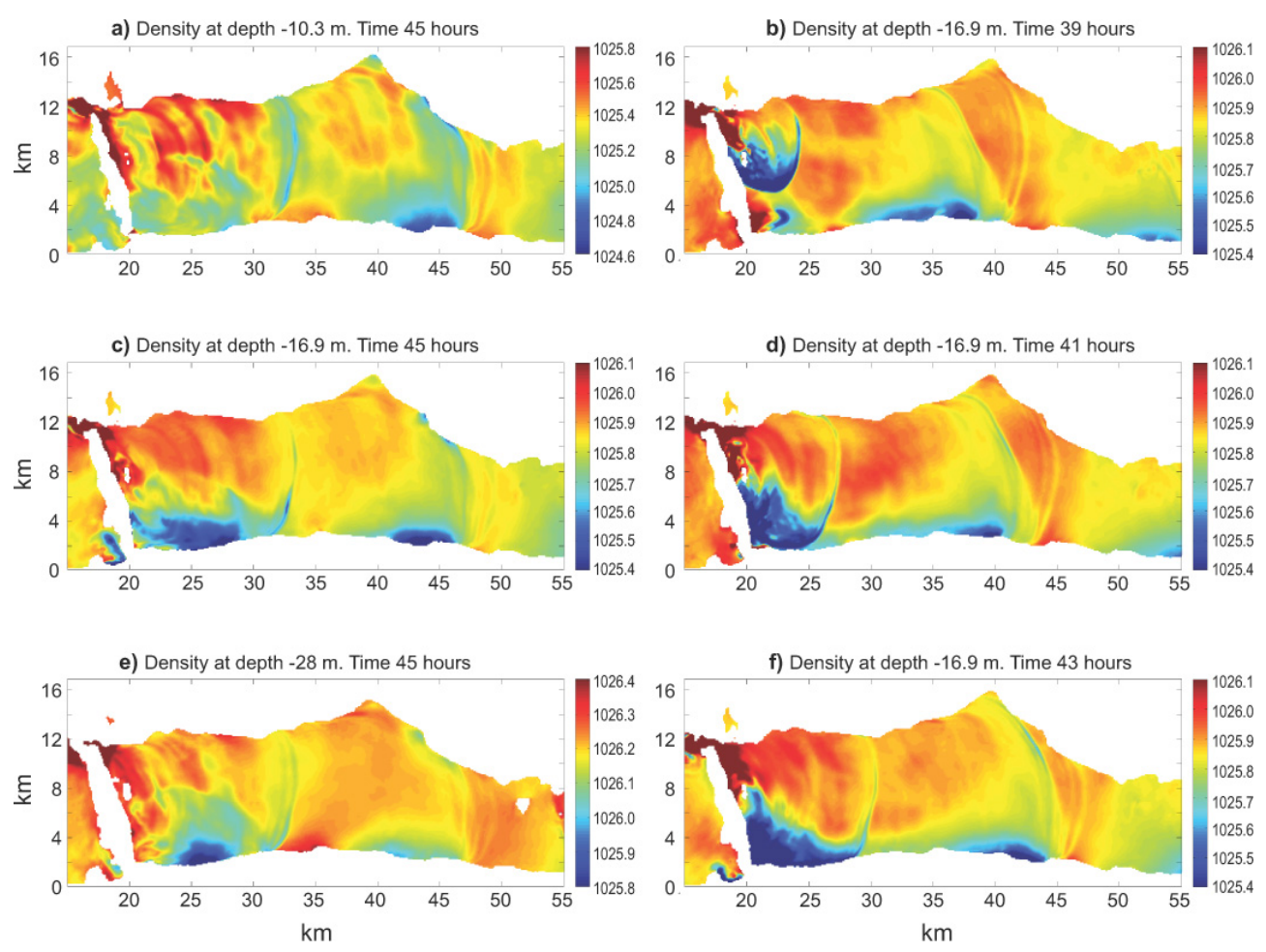

Fig. 16. Horizontal plot of density $\left[\mathrm{kg} \mathrm{m}^{-3}\right]$, Van Mijenfjorden (VMrun1). Left: $45 \mathrm{~h}$ simulated; depth $10.3 \mathrm{~m}$ (a), $16.9 \mathrm{~m}$ (c), $28 \mathrm{~m}$ (e). Right: depth $16.9 \mathrm{~m} ; 39 \mathrm{~h}$ (b), $41 \mathrm{~h}(\mathbf{d}), 43 \mathrm{~h}(\mathbf{f})$.

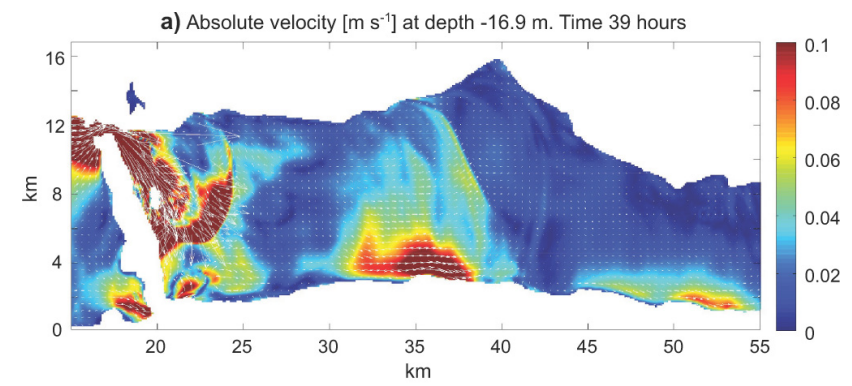

b) Absolute velocity $\left[\mathrm{m} \mathrm{s}^{-1}\right]$ at depth $-16.9 \mathrm{~m}$. Time 45 hours

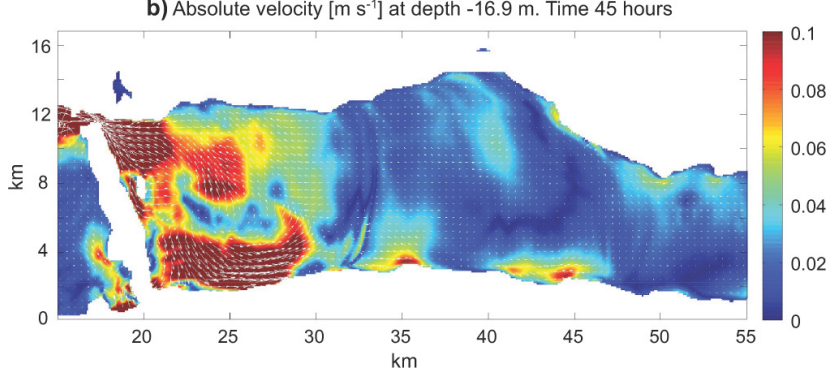

Fig. 17. Current magnitude $\left[\mathrm{ms}^{-1}\right]$ and direction for VMrun 1 at $16.9 \mathrm{~m}$ depth. Simulated $39 \mathrm{~h}$ (a) and $45 \mathrm{~h}$ (b).

non-hydrostatic, small-scale overturning and mixing near the sills (Berntsen et al., 2009), as observed just inside Akselsundet. Our observations do not resolve the near field mixing processes in the vicinity of the sill. It is expected that
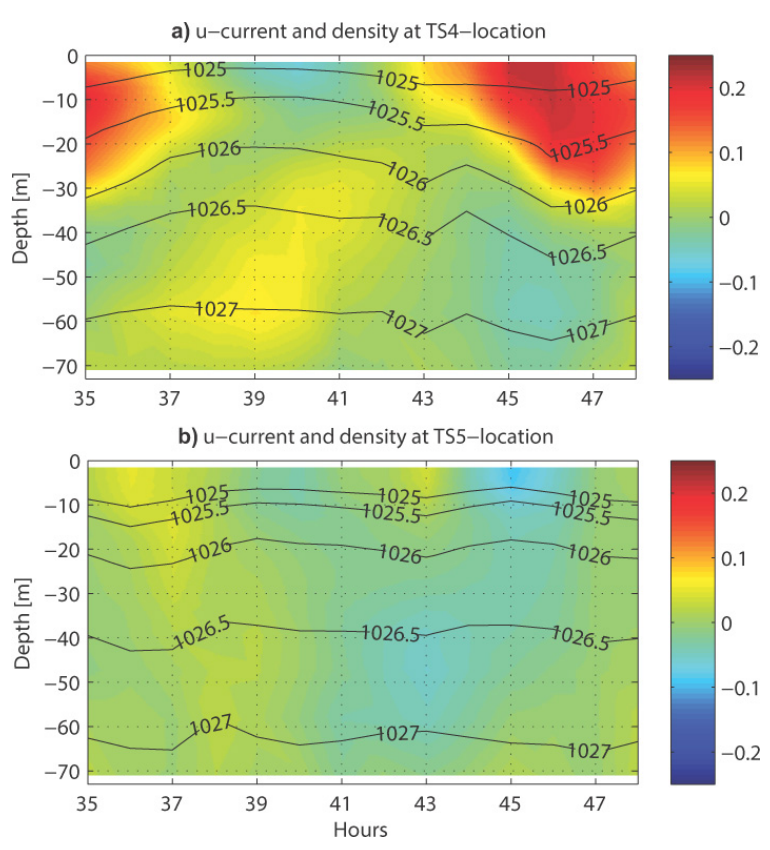

Fig. 18. Along-coastal current $\left[\mathrm{ms}^{-1}\right]$ (colour) and density $\left[\mathrm{kg} \mathrm{m}^{-3}\right]$ (black lines) at locations TS4 (a) and TS5 (b) from VMrun $1,35-48 \mathrm{~h}$ simulated.

the energy lost to mixing will be unavailable for generation of the long internal wave, influencing the resulting in-fjord wave field. Farmer and Armi (1999, 2001), using detailed 

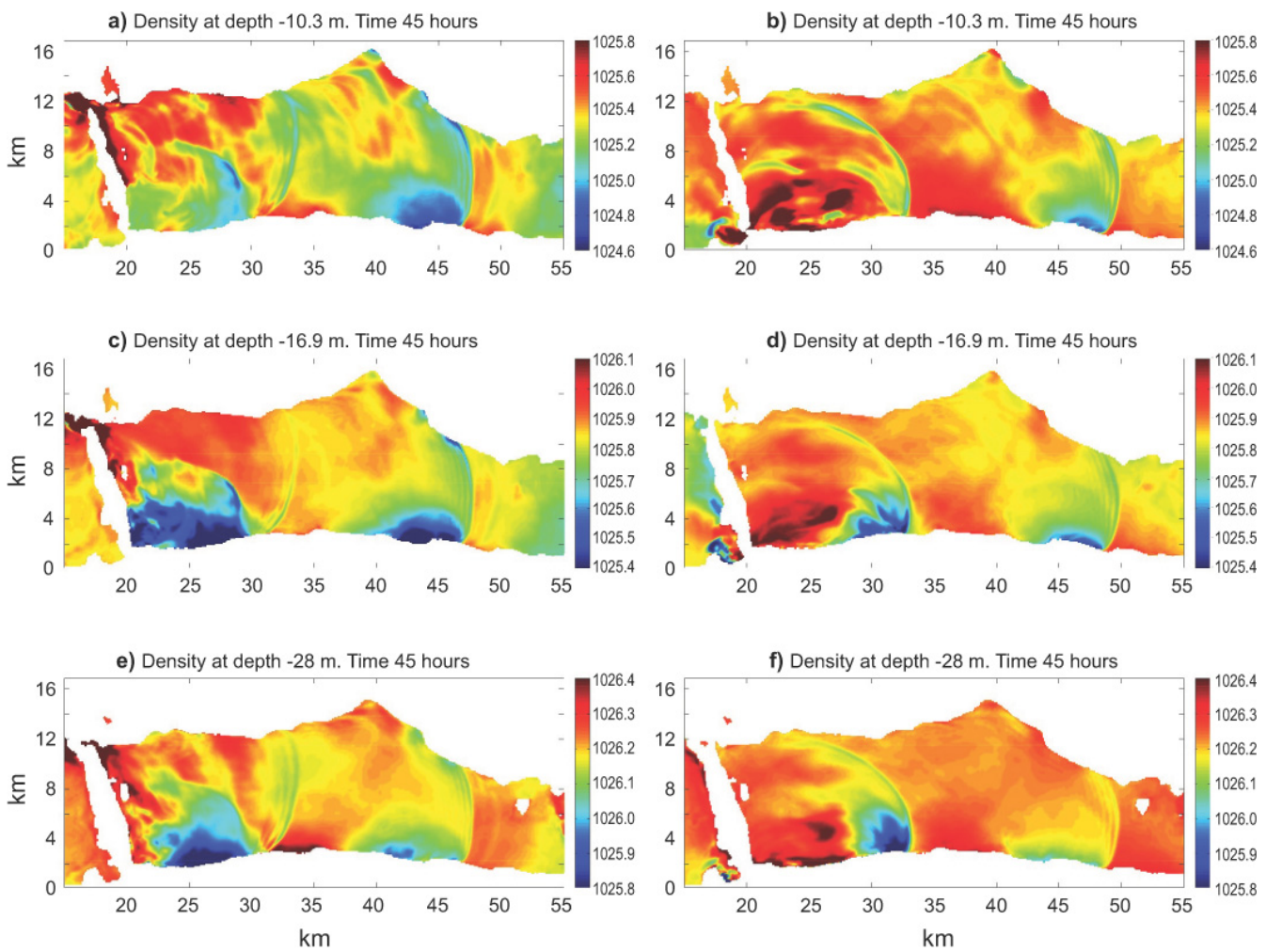

Fig. 19. Horizontal plot of density $\left[\mathrm{kg} \mathrm{m}^{-3}\right]$. Left: Mariasundet closed (VMrun2). Right: Akselsundet closed (VMrun3). (a) and (b) 10.3 m, (c) and (d) $16.9 \mathrm{~m}$, (e) and (f) $28 \mathrm{~m}$.

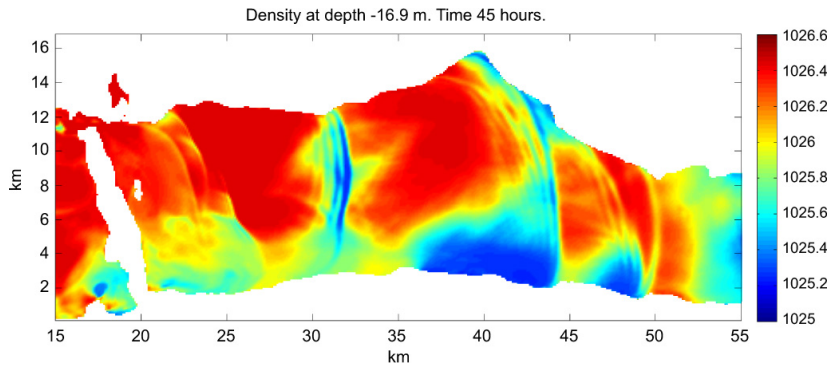

Fig. 20. Horizontal plot of density $\left[\mathrm{kg} \mathrm{m}^{-3}\right]$ after $45 \mathrm{~h}$ simulation, $16.9 \mathrm{~m}$ depth. Two-layer hydrography profile (VMrun4).

observations, explain the time-dependent evolution of the stratified flow response over a sill that is typically not captured by the numerical simulations because of unresolved mixing. Rapid flow over the sill separates the streamlines into a fast deep current immediately downstream of the crest, beneath a spreading, weakly stratified, nearly stagnant intermediate wedge susceptible to overturning and further mixing. Small scale instability and boundary layer separation act in concert to determine the time evolution of the flow. Numerical studies, e.g. Berntsen et al. (2009), examine the resulting lee waves as a result of varying grid sizes, and thus the ability of the model to resolve the aforementioned mixing. They report a distinct difference in the lee wave field moving from
100 to $12.5 \mathrm{~m}$ resolution; as the resolution increases, waves become shorter in scale and their amplitudes increase. For the smaller scales, the vortices in the wedge zone increase in intensity. In all their experiments, Berntsen et al. (2009) reported boundary layer separation, a well-mixed wedge and internal waves in the lee of the sill; however, those in the hydrostatic and relatively coarser resolution runs were a result of artificial mixing, whereas the high-resolution nonhydrostatic models resolved the mixing processes. In our simulations, it would be of interest to apply a nested grid, where resolution is increased near the sounds, in order to resolve the mixing.

One must take care when directly comparing the observations to the model results, due to the numerous and crude assumptions involved. Firstly, we neglected wind. Thus, the modelled near-surface turbulence distribution and currents are bound to differ from the measured data. Another important aspect of the wind is that it may set up internal waves upon changing direction. Wind measurements during the cruise (Fig. 2) show that the wind direction in Van Mijenfjorden is unidirectional for long periods of time, which sets up a tilting interface that when released (as a result of wind changes), will propagate along the coast as an internal Kelvin wave. A second aspect is that our model is started from rest and is run for $48 \mathrm{~h}$ in an attempt to isolate the effect of internal wave propagation on an otherwise undisturbed system. In 
order for a mean circulation pattern to be set up, one would need a spin-up time of several days, possibly months. In addition, the model does not resolve the estuarine circulation properly, and large-scale pressure gradients from outside the fjord region, bar the tidal contribution, are also absent in the simulation. These shortcomings are all likely candidates for explaining why the observed mean currents in Fig. 4e) are not captured in the model. However, this might just as well be another example of insufficient resolution not resolving small-scale overturning and mixing from e.g. wind and background shear.

The wave pulse observed in the model results demands some discussion. When the conditions are near super-critical, a wave pulse propagates inward from the fjord entrance at the beginning of each inflow phase of the tidal cycle. This pulse of steep front is not dominantly affected by rotation, propagates with the long internal wave speed, and the leading crest is followed by a series of smaller amplitude waves. The train of waves develops as a result of dispersion, since the group velocity of the shorter waves is smaller than the long wave speed. The waves are characterized as non-linear internal solitons. The process is similar to that for free surface waves which are comparatively less non-linear. The latter has been illustrated comparing fully nonlinear computations and KdVformulation (Grue et al., 2008), and similar generation process for internal waves was computed using fully nonlineardispersive calculations in Grue (2005). The vertical velocity profiles of the two-layer solitary wave are described in detail in Grue et al. (1999). The upper and lower layer velocities are in opposite directions, with an abrupt change across the interface. This may be compared to our observations, i.e Fig. 4d), where a similar separation of velocities is seen. It should be kept in mind, however, that the KdV-theory is applicable to two-layer solitons with non-dimensional excursions of up to 0.4 (Grue et al., 1999; Grue, 2005). In our study, results from both observations and the numerical simulations indicate normalized excursions up to 1 , exceeding the validity of the KdV-formulation. It must be emphasized that the hydrography in Van Mijenfjorden varies considerably, and the profile at TS4 cannot be characterized by a two-layer system. Thus, caution must be exercised in the idealized theoryobservation comparison.

The generation process for internal solitons as explained in Cummins et al. (2003) and Grue (2005) is as follows: during intense outflow, an internal depression forms over the sill crest, accompanied by an elevation more upstream. When the outflow relaxes, the depression propagates upstream into the fjord. Interestingly, as flow is supercritical during both inand outflow through Akselsundet, we might expect solitons emerging on both sides of the sound at opposite phases of the tidal cycle. The dispersive degeneration of the solitary front into smaller waves is not properly resolved. An additional test with non-hydrostatic dynamics turned on yielded little difference in the results, which is expected due to insufficient horizontal resolution.
Acknowledgements. The authors are grateful to Jarle Berntsen and Jiuxing Xing for valuable input on the model configuration, and the captain and crew of RV Håkon Mosby during the field work. This study is partly supported by the Research Council of Norway, through the "Internal hydraulic processes in an Arctic fjord" project. The comments from two reviewers helped to improve an earlier version of the manuscript.

Edited by: Y. Troitskaya

Reviewed by: J. Berntsen and J. Grue

\section{References}

Adcroft, A., Hill, C., and Marshall, J.: Representation of Topography by Shaved Cells in a Height Coordinate Ocean Model, Mon. Weather Rev., 125, 2293-2315, doi:10.1175/15200493(1997)125<2293:rotbsc>2.0.co;2, 1997.

Adcroft, A., Hill, C., Campin, J.-M., Marshall, J., and Heimbach, P.: Overview of the formulation and numerics of the MITgcm, in: Proceedings of the ECMWF seminar series on Numerical Methods, Recent developments in numerical methods for atmosphere and ocean modelling, ECMWF, 139-149, 2004.

Beletsky, D., O'Connor, W. P., Schwab, D. J., and Dietrich, D. E.: Numerical simulation of internal Kelvin waves and coastal upwelling fronts, J. Phys. Oceanogr., 27, 1197-1215, 1997.

Bergh, J.: Measured and modelled tidally driven mean circulation under ice cover in Van Mijenfjorden, M.Sc. thesis, Department of Oceanography, Göteburg University, Göteburg, Sweden, 65 pp., 2004.

Berntsen, J., Xing, J., and Davies, A.: Numerical studies of flow over a sill: sensitivity of the non-hydrostatic effects to the grid size, Ocean Dynam., 59, 1043-1059, doi:10.1007/s10236-0090227-0, 2009.

Boegman, L. and Dorostkar, A.: Three-dimensional simulation of NLIW generation, propagation and breaking in Cayuga Lake, in: 7th Int. Symp. on Stratified Flows, Rome, Italy, 22-26 August 2011.

Brown, P. J.: Kelvin-wave reflection in a semi-infinite canal, J. Mar. Res., 31, 1-10, 1973.

Cottier, F. R., Nilsen, F., Skogseth, R., Tverberg, V., Skarðhamar, J., and Svendsen, H.: Arctic fjords: a review of the oceanographic environment and dominant physical processes, Geological Society, London, Special Publications, 344, 35-50, doi:10.1144/sp344.4, 2010.

Cummins, P. F., Vagle, S., Armi, L., and Farmer, D. M.: Stratified flow over topography: upstream influence and generation of nonlinear internal waves, P. Roy. Soc. Lond. A Mat., 459, 1467-1487, 10.1098/rspa.2002.1077, 2003.

Farmer, D. and Armi, L.: Stratified flow over topography: the role of small-scale entrainment and mixing in flow establishment, P. Roy. Soc. Lond. A Mat., 455, 3221-3258, 1999.

Farmer, D. M. and Armi, L.: Stratified flow over topography: models versus observations, P. Roy. Soc. Lond. A Mat., 457, 28272830, doi:10.1098/rspa.2001.0802, 2001.

Farmer, D. M. and Freeland, H. J.: The physical oceanography of fjords, Prog. Oceanogr., 12, 147-220, 1983.

Fer, I. and Widell, K.: Early spring turbulent mixing in an icecovered Arctic fjord during transition to melting, Cont. Shelf Res., 27, 1980-1999, 2007. 
Fer, I., Skogseth, R., and Geyer, F.: Internal waves and mixing in the Marginal Ice Zone near the Yermak Plateau, J. Phys. Oceanogr., 40, 1613-1630, 2010.

Fjellsbø, T. K. B.: Circulation, mixing and tidally-induced energy fluxes in Van Mijenfjorden, M.Sc. thesis, Geophysical Institute, University of Bergen, Bergen, Norway, 98 pp., 2013.

Gill, A. E.: Atmosphere-Ocean Dynamics, Academic Press, London, 662 pp., 1982.

Gómez-Giraldo, A., Imberger, J., and Antenucci, J. P.: Spatial structure of the dominant basin-scale internal waves in Lake Kinneret, Limnol. Oceanogr., 51, 229-246, 2006.

Griffies, S. M. and Hallberg, R. W.: Biharmonic Friction with a Smagorinsky-Like Viscosity for Use in Large-Scale EddyPermitting Ocean Models, Mon. Weather Rev., 128, 2935-2946, doi:10.1175/1520-0493(2000)128<2935:BFWASL>2.0.CO;2, 2000.

Grue, J.: Generation, propagation, and breaking of internal solitary waves, Chaos, 15, 037110, doi:10.1063/1.2047907, 2005.

Grue, J., Jensen, A., Risås, P.-O., and Sveen, J. K.: Properties of large-amplitude internal waves, J. Fluid Mech., 380, 257-278, doi:10.1017/S0022112098003528, 1999.

Grue, J., Pelinovsky, E. N., Fructus, D., Talipova, T., and Kharif, C.: Formation of undular bores and solitary waves in the Strait of Malacca caused by the 26 December 2004 Indian Ocean tsunami, J. Geophys. Res., 113, C05008, doi:10.1029/2007jc004343, 2008.

Guthrie, J. D., Morison, J. H., and Fer, I.: Revisiting internal waves and mixing in the Arctic Ocean, J. Geophys. Res., 118, 39663977, doi:10.1002/jgrc.20294, 2013.

Helfrich, K. R. and Melville, W. K.: Long nonlinear internal waves, Annu. Rev. Fluid. Mech., 38, 395-425, doi:10.1146/annurev.fluid.38.050304.092129, 2006.

Hodges, B. R., Imberger, J., Saggio, A., and Winters, K. B.: Modeling basin-scale internal waves in a stratified lake, Limnol. Oceanogr., 45, 1603-1620, 2000.

Inall, M., Cottier, F., Griffiths, C., and Rippeth, T.: Sill dynamics and energy transformation in a jet fjord, Ocean Dynam., 54, 307314, doi:10.1007/s10236-003-0059-2, 2004.

Legg, S. and Adcroft, A.: Internal Wave Breaking at Concave and Convex Continental Slopes*, J. Phys. Oceanogr., 33, 2224-2246, doi:10.1175/1520-0485(2003)033<2224:IWBACA>2.0.CO;2, 2003.

Llewellyn Smith, S. G.: Stratified rotating edge waves, J. Fluid Mech., 498, 161-170, doi:10.1017/S002211200300702X, 2004.

Marchenko, A. V., Morozov, E. G., Muzylev, S. V., and Shestov, A. S.: Interaction of Short Internal Waves with the Ice Cover in an Arctic Fjord, Oceanology, 50, 18-27, doi:10.1134/S0001437010010029, 2010.

Marshall, J., Adcroft, A., Hill, C., Perelman, L., and Heisey, C.: A finite-volume, incompressible Navier Stokes model for studies of the ocean on parallel computers, J. Geophys. Res., 102, 57535766, doi:10.1029/96jc02775, 1997.

Maxworthy, T.: Experiments on solitary internal Kelvin waves, J. Fluid Mech., 129, 365-383, 1983.

Morozov, E. G. and Marchenko, A. V.: Short-period internal waves in an arctic Fjord (Spitsbergen), Izv. Atmos. Ocean. Phys., 48, 401-408, doi:10.1134/s0001433812040123, 2012.
Nash, J. D., Alford, M. H., and Kunze, E.: Estimating internal wave energy fluxes in the ocean, J. Atmos. Ocean. Tech., 22, 15511570, 2005.

Padman, L. and Dillon, T. M.: Turbulent mixing near the Yermak Plateau during the coordinated Eastern Arctic Experiment, J. Geophys. Res., 96, 4769-4782, 1991.

Padman, L. and Erofeeva, S.: A barotropic inverse tidal model for the Arctic Ocean, Geophys. Res. Lett., 31, L02303, doi:10.1029/2003gl019003, 2004.

Rainville, L. and Woodgate, R. A.: Observations of internal wave generation in the seasonally ice-free Arctic, Geophys. Res. Lett., 36, L23604, doi:10.1029/2009GL041291, 2009.

Renouard, D. P., D’Hières, G. C., and Zhang, X.: An experimental study of strongly nonlinear waves in a rotating system, J. Fluid Mech., 177, 381-394, 1987.

Skarðhamar, J. and Svendsen, H.: Short-term hydrographic variability in a stratified Arctic fjord, Geological Society, London, Special Publications, 344, 51-60, doi:10.1144/sp344.5, 2010.

Stashchuk, N., Inall, M., and Vlasenko, V.: Analysis of supercritical stratified tidal flow in a Scottish Fjord, J. Phys. Oceanogr., 37, 1793-1810, doi:10.1175/jpo3087.1, 2007.

Stigebrandt, A.: Some aspects of tidal interaction with fjord constrictions, Estuar. Coast. Mar. Sci., 11, 151-166, doi:10.1016/S0302-3524(80)80038-7, 1980.

Stigebrandt, A. and Aure, J.: Vertical mixing in basin waters of fjords, J. Phys. Oceanogr., 19, 917-926, 1989.

Støylen, E. and Weber, J. E. H.: Mass transport induced by internal Kelvin waves beneath shore-fast ice, J. Geophys. Res., 115, C03022, doi:10.1029/2009jc005298, 2010.

Svendsen, H., Beszczynska-Møller, A., Hagen, J. O., Lefauconnier, B., Tverberg, V., Gerland, S., Ørbøk, J. B., Bischof, K., Papucci, C., Zajaczkowski, M., Azzolini, R., Bruland, O., Wiencke, C., Winther, J.-G., and Dallmann, W.: The physical environment of Kongsfjorden-Krossfjorden, an Arctic fjord system in Svalbard, Polar Res., 21, 133-166, doi:10.1111/j.17518369.2002.tb00072.x, 2002.

Vlasenko, V. and Stashchuk, N.: Three-dimensional shoaling of large-amplitude internal waves, J. Geophys. Res., 112, C11018, doi:10.1029/2007jc004107, 2007.

Vlasenko, V., Stashchuk, N., Hutter, K., and Sabinin, K.: Nonlinear internal waves forced by tides near the critical latitude, DeepSea Res. Pt. I, 50, 317-338, doi:10.1016/s0967-0637(03)000189, 2003.

Weber, J. E. H. and Støylen, E.: Mean drift velocity in the Stokes interfacial edge wave, J. Geophys. Res., 116, C04002, doi:10.1029/2010jc006619, 2011.

Widell, K.: Ice-ocean interaction and the under-ice boundary layer in an Arctic fjord, Ph.D. thesis,, Geophys. Inst., University of Bergen, Bergen, Norway, 2006.

Xing, J. and Davies, A. M.: On the importance of non-hydrostatic processes in determining tidally induced mixing in sill regions, Cont. Shelf Res., 27, 2162-2185, doi:10.1016/j.csr.2007.05.012, 2007. 